\title{
EXPERIMENTAL AND MODELING EVALUATION OF DROPLET SIZE IN IMMISCIBLE LIQUID-LIQUID STIRRED VESSEL USING VARIOUS IMPELLER DESIGNS
}

Reza Afshar Ghotli, Mohammad Reza Abbasi, AmirHossein Bagheri, Abdul Aziz Abdul Raman*, Shaliza Ibrahim, Huseyin Bostanci

\section{Reza Afshar Ghotli}

Institute of Ocean and Earth Sciences (IOES), Research Management \& Innovation Centre, University of Malaya, 50603 Kuala Lumpur, Malaysia

Email: afsharghotli_reza@yahoo.com

2. Mohammad Reza Abbasi

Department of Chemical Engineering, Faculty of Engineering, University of Malaya, 50603 Kuala Lumpur, Malaysia, Email: $\underline{\text { m abbasi@ifac-mail.com }}$

\section{AmirHossein Bagheri}

Department of Mechanical and Energy Engineering, University of North Texas, Denton, TX 76207, U.S.A., Email: Amirhossein.Bagheri@unt.edu

\section{Abdul Aziz Abdul Raman (Corresponding Author)}

Department of Chemical Engineering, Faculty of Engineering, University of Malaya, 50603

Kuala Lumpur, Malaysia, Email: azizraman@um.edu.my

\section{Shaliza Ibrahim}

Institute of Ocean and Earth Sciences (IOES), Research Management \& Innovation Centre, University of Malaya, 50603 Kuala Lumpur, Malaysia, Email: shaliza@um.edu.my

6. Huseyin Bostanci

Department of Engineering Technology, University of North Texas, Denton, TX 76207, U.S.A. Email: Huseyin.Bostanci@unt.edu 


\begin{abstract}
The present study investigates the effects of impeller design and dispersed phase volume ratio on mean drop sizes $\left(d_{32}\right)$ in immiscible liquid-liquid stirred vessel through experimental and modeling approaches. Various impeller designs including conventional and new impeller designs were employed to cover both radial and axial flow impellers. The microscopic method associated with image processing tools was used for the drop size analysis. The results showed the hydrofoil impeller produced the largest drop sizes while the double-curved blade turbine produced the smallest drop sizes, corresponding to about $37 \%$ difference. Increasing the dispersed phase volume ratio from $1 \%$ to $10 \%$ ) increased the $\mathrm{d}_{32}$ by approximately 20 to $40 \%$. Adaptive neurofuzzy inference system based on fuzzy C-means (ANFIS-FCM) clustering algorithm was used to develop a model to predict drop sizes, and its validation and accuracy were examined by comparing the results to the experimental data. The results also proved the superior prediction capability of the ANFIS-FCM method over the empirical correlations for the most cases.
\end{abstract}

KEYWORDS: Impeller Design; Drop size measurement; Image analysis; Empirical correlation; ANFIS-Fuzzy C-Means 


\section{Introduction}

Liquid-liquid mixing in stirred vessels and mixing of two immiscible liquids in the turbulent-flow condition are typical processes in various chemical, pharmaceutical, petroleum and food process applications. Examples of liquid-liquid mixing in industrial processes include polymerization, emulsification, and solvent extraction. In all these cases, drop size distribution is amongst the most significant parameters to evaluate the dispersion stability and the efficiency of the system operation. Furthermore, it plays a key role to generate interfacial areas in order to determine the mass transfer rate between the phases in liquid-liquid systems [1-3]. Smaller drop sizes become more beneficial in mass transfer processes where they generate larger interfacial and mass transfer areas around the impeller area compared to drops with larger size $[4,5]$. The drop size distribution has consequences of the dynamic equilibrium between the drop break up and coalesce [6, 7]. Fundamentally, drop breakage is initiated by the collision between droplets and eddies whereas coalescence is caused by the collision between droplets [8].

In the meantime, mechanical agitation systems are utilized as ordinary tools for mixing processes [9-13]. It is well-known that the input parameters such as the impeller type, dispersed phase volume fraction, agitation speed, and fluids physical properties influence droplet sizes and consequently, the interfacial areas. The literature clearly states that the increase in dispersed phase holdup causes faster coalescence rate due to higher collision rates and rheological changes and therefore, longer contact intervals for droplets [10]. Thus, a suitable design for mixing systems needs to expand knowledge on mechanical properties and fluid properties to control the drop size and uniformity of the distribution [11].

There are few studies systematically comparing the mean drop sizes produced by different designs of impellers. In fact, most of the reported experiments in liquid-liquid dispersion 
have been accomplished with Rushton turbine [14-16]. Although using different designs of impellers has been receiving interest recently, available data are still limited $[11,14,16,17]$. Drop size study in a highly dilute liquid-liquid system was carried out by Zhou and Kresta [18] with a Rushton turbine and three axial flow impellers without any reports on the comparison between the impellers. Much smaller drop sizes were reported for EKATO mizer-disk generated than a Rushton turbine at the same diameter and specific power by Beck [19]. Pacek et al. [14] studied the effect of different types of impellers including Rushton turbine, disk turbine and four Chemineer impellers on drop size distribution. The results for viscous and non-viscous dispersed phase systems with volume fraction of $1 \%$ and $5 \%$ showed the same drop sizes for low-power impellers at the same mean specific energy dissipation rate which was much smaller than the Rushton turbine and disk turbine outcomes. They also postulated that low power-number impellers generate smaller drop sizes due to shorter circulation time that can lead the drops to the impeller region regularly. Musgrove et al. [20] verified smaller average drop size $\left(d_{32}\right)$ for hydrofoil impellers (Lightnin A310, Chemineer, and HE3) than the turbine impellers (Rushton turbines and pitched-blade turbines) at the same power per unit volume and impeller diameter. Kraume et al. [8] reported larger droplet size with increasing the dispersed phase holdup from 0.05 to 0.5 . They also stated there was no linear relationship between drop sizes and dispersed phase holdup at higher dispersed phase ratios. Giapos et al. [3] reported about 52\% increase in the mean drop sizes $\left(d_{32}\right)$ and wider drop size distribution along with reduction in the number of impeller blades from 8 to 2 for a system of kerosene and distilled water with low dispersed phase holdup. A reduction tendency in maximum and the mean drop sizes was obtained by Lovick et al. [21] by increasing the agitation speed in mixtures of tap water and kerosene using a sixbladed Rushton turbine for up to $60 \%$ dispersed phase at the speeds of $350-550 \mathrm{rpm}$. They also observed insignificant effect of phase fractions on drop sizes which was inconsistent 
with the prior statements. Comparing the drop size of the disk and open styles of six-flat blade impellers by Sechremeli et al. [7] implied 6 to $82 \%$ larger drops for open style impellers at the same impeller diameter and agitation speed for a system of distilled water and kerosene. They mentioned that the larger power consumption would generate greater turbulence and result in more drop breakage. Podgórska [12] obtained much smaller droplets for hydrofoil impellers (Lightnin A310 and a Chemineer HE3) at equal power input per mass for low and high dispersed phase viscosity system and compared the outcomes with the Rushton disc, 4-bladed and 2-bladed $45^{\circ}$ pitched blade, and 4-bladed $60^{\circ}$ degree pitched blade turbines. El-Hamouz [10] compared the emulsification of the oil with the viscosity of 242 mPa.s by the Sawtooth and PBT impellers featuring the same diameter size. The greater power-number results in higher mean energy and therefore smaller particle sizes. However, in contrast to their expectation and Pacek et al. [14] results, smaller drop sizes were observed for the impeller with lower power-numbers. This unexpected outcome might indicate a substantial role of local shear on drop breakage than turbulent shear. A reduction in the breakage-rate and an increase in the mean drop sizes $\left(\mathrm{d}_{32}\right)$ in high concentration dispersed phases were reported by El-Hamouz et al. [11]. Moreover, increasing the dispersed phase holdup did not indicate any considerable effect on the equilibrium of $\mathrm{d}_{32}$. They also stated a linear relation between the $\mathrm{d}_{32}$ and dispersed phase holdup. Afshar Ghotli et al. [22] pointed out drop sizes would reduce as the curvature angle and central disc sizes in curved blade impellers decrease.

Various models and theories have been provided to predict drop size in turbulent liquidliquid stirred vessels based on different operating conditions and parameters. Evaluating the effect of impeller design on drop size is complicated due to the difficulties in drop coalescence modeling [22]. When the inertial stress is greater than the interfacial tension 
stress in drop break up, the largest drop size in turbulent condition could be estimated by Kolmogorov's local isotropy theory [23-25]. The maximum drop size $\left(\mathrm{d}_{\max }\right)$ is correlated to dimensionless Weber number [14, 26].

$\frac{d_{\max }}{D}=C_{1} W e^{-0.6}$

Where $D$ is the impeller diameter, $C_{l}$ is the dimensionless constant and $W e$ is the dimensionless Weber number. The Weber number shows the turbulence intensity and the physicochemical properties of the system [10].

$W e=\frac{\rho_{c} N^{2} D^{3}}{\sigma}$

Sprow [29] proved that the mean drop sizes only depends on the maximum drop size [28]. Afterwards, most of the published experimental studies have reported that the maximum drop size is proportional to $\mathrm{d}_{32}$ due to a linear correlation between them [11, 13, 28-30];

$\frac{d_{32}}{D}=C_{2} W e^{-0.6}$

Where $C_{2}$ is the dimensionless constant obtained experimentally depending on the tank geometry and impeller type [12]. These expressions have been verified for a system with low dispersed phase holdup $(<0.05)$ due to the assumption of equilibrium condition for both Hinze's and Kolmogorov's theories developed. In this condition, the rate of coalescence can be neglected $[12,14,24]$. Therefore, other expressions have been developed to evaluate $d_{\max }$ or $d_{32}$ to overcome these limitations, and they have taken coalescence into account in the system $[8,24]$. The modified form of the Hinze [31] model $\left(\mathrm{d}_{32} \sim \mathrm{We}^{-0.6}\right)$ was reported for most of the experimental works involved with dispersed phase hold up; 


$$
\frac{d_{32}}{D}=C_{4}\left(1+C_{3} \varphi_{d}\right) W e^{-a}
$$

Where $\varphi_{\mathrm{d}}$ represents the dispersed phase volume fraction and $C_{3}$ and $C_{4}$ depend on the coalescence tendency and the impeller type respectively. High values of $C_{3}$ verify the tendency of system to coalesce easily whereas the low values show the slow coalescence systems. The values of $C_{3}$ vary between 3 and 20 [8, 32, 33]. Kraume et al. [8] discovered a significant change in the Weber number exponent due to increase in the phase ratio because of the coalescence effect. In order to consider the effect of viscosity, the following semiempirical equation was correlated by Calabrese et al. [27] to predict $\mathrm{d}_{32}$ values based on the large amount of experimental data;

$$
\frac{d_{32}}{D}=C_{5}\left(1+C_{6} \varphi_{d}\right) W e^{-0.6}\left[1+C_{7}\left(1-C_{8} \varphi_{d}\right) V_{i}\left(\frac{d_{32}}{D}\right)^{0.33}\right]^{0.6}
$$

Where the viscous number, $V_{i}$ representing the ratio of viscous to surface forces is evaluated from equation 6 ;

$$
V_{i}=\frac{\mu_{d} N D}{\sigma}\left(\frac{\rho_{c}}{\rho_{d}}\right)^{0.5}
$$

The authors reported the value of $0.054,3,4.42$, and 2.5 for $\mathrm{C}_{5}, \mathrm{C}_{6}, \mathrm{C}_{7}$, and $\mathrm{C}_{8}$ respectively. Although several reports on the effect of impeller design on drop size measurement can be found in the literature, few of them considered various impeller designs.

Accordingly, the purpose of this work is to provide the experimental data and accurate models to predict the drop size in a typical immiscible liquid-liquid system with different impeller designs. The effect of impeller design and dispersed phase ratio has been studied. 
Adaptive neuro-fuzzy inference system based on fuzzy c-means clustering algorithm (ANFIS-FCM) is one of the robust artificial intelligence algorithms proved to be highly successful in recognition of relationships between input and output parameters. This approach is followed to develop a model which can accurately predict the drop size. The results from ANFIS-FCM model and empirical correlations are compared to evaluate their prediction capabilities against experimental data.

\section{$2 \quad$ Materials and methods}

\subsection{Materials}

RBD Palm oil used in the current study was purchased from Sik Cheong Edible Oil Sdn. Bhd., Malaysia. The sodium dodecyl sulfate (SDS) in powder form was used as a surfactant, supplied by Merck Chemicals Co., Germany. Palm oil with the nominal viscosity of 0.08198 mPa.s and density of $890 \mathrm{~kg} \cdot \mathrm{m}^{-3}$ was used as the dispersed phase. Table 1 presents the physical properties of the continuous and dispersed phases in the experiments.

Table 1. physical properties of the continuous and dispersed phases

\subsection{Experimental setup}

In this study, a flat bottom transparent scratch proof Perspex vessel with $0.3 \mathrm{~m}$ diameter (T) was employed. The vessel was equipped with four equally spaced wall mounted baffles with the width (B) of $\mathrm{B}=\mathrm{T} / 10$. The ratio of impeller clearance (C) to tank diameter (T) followed the standard geometries and was equivalent to $0.1 \mathrm{~m}$. A speed controller system with the accuracy of $0.04 \pm 2 \%$ was used to adjust and control the agitation speed. The power consumptions were measured using a suspended motor system and power analyzer (Model 6830A Prova, Taiwan). Various design of impellers with the same diameter, namely, Rushton turbine (RT), $45^{\circ}$ up-flow pitched-blade turbine (PBTU), $45^{\circ}$ down-flow pitched-blade 
turbine (PBTD), semicircular blade turbine (CB), elliptical blade turbine (EB), parabolic blade turbine (PB), and hydrofoil impeller (HE3) in addition to newly developed double circular blades turbine (DCB) were utilized. These impellers were selected to cover axial and radial flow impellers, up-flow and down flow impellers, and conventional and new impeller designs. The hydrofoil impeller and pitched-blade turbines are axial flow impellers. Besides, the Rushton turbine, semicircular blade, double circular blade, parabolic blades are belonging to the radial flow impellers. Rushton turbine, up and down flow pitched blade turbines have been commonly used through the past decades. On the other hand, curved blade, elliptical blade, parabolic blade and 3-blade hydrofoil impeller have been tried recently and the last one, double curved blade impeller has not been employed. The impeller diameter was equal to $T / 3$ for all of the impellers. The schematic and description of each impeller are shown in Figure 2 and Table 2, respectively.

\author{
Fig. 1. Experimental setup; A) Motor, B) Shaft, C) Impeller, D) Tank, E) Speed analyzer, F) \\ Power analyzer
}

Fig. 2. The impeller designs evaluated

Table 2. Description of the investigated impellers in the experimental part

\title{
2.3 Experimental procedure
}

The effect of various impeller designs on drop sizes in a mixture of distilled water and palm oil with $1 \%, 3 \%, 5 \%$ and $10 \%$ holdup fraction were investigated experimentally. The experiments were carried out at atmospheric pressure and the constant temperature of $26^{\circ} \mathrm{C}$. The temperature in the stirred vessel was controlled with a water bath circulation system to make sure that there were no significant changes in the process condition. The liquid height 
was equal to the tank diameter (T). Commonly, low dispersed-phase system and surfactant are used to reduce and eliminate coalescence in the system. The Sodium dodecyl sulfate (SDS) was chosen as a surfactant in this work [10]. Approximately $0.3 \% \mathrm{w} / \mathrm{w}$ of the surfactant was diluted in to the distilled water to prepare the surfactant solution [34]. After a short period of agitation the required amount of oil was added gently onto the top surface of the mixture of water and surfactant [10]. All the experiments were carried out in the same power consumption rate. The agitation speeds were selected under impeller aeration point to prevent surface aeration during the experiments [6]. The sampling point was set to $0.02 \mathrm{~m}$ above the impeller level due to higher drop break-up rate around the impeller region compared to the other points in the stirred vessel [15]. Samples were taken after 20, 40, 60, 80 and 100 minutes of mixing. Samplings were repeated at the same time interval to prevent any changes on Sauter mean diameter with time. The tanks and sampling tubes were taken apart and washed with a detergent and acetone after conducting the experiments. Afterwards, they were repeatedly washed with water to remove any trace contaminants.

The extracted samples from the stirred vessel are analyzed through the microscopic method. This method is capable to detect drops in the range of $17-1000 \mu \mathrm{m}$ depending on the microscope lens. Leica optical camera microscope (DF290) at a magnification of 20X and 10X was utilized to visually evaluate drop sizes. The images taken in this work were analyzed using image processing tools in $\mathrm{MATLAB}^{\circledR}$ for each time period. In the digital world, images are described in three main colors (red, green, and blue (RGB)) where each pixel carries an RGB matrix and its location in an image. In the process of the image analysis, the first step is to remove the background color which is defined as the more repeated color in the image and described as an RGB matrix. Therefore, the image contrast is elevated, and the background color matrix is subtracted from the main image. Afterwards, the images need to 
be converted to the binary format which only two colors exist; "black" and "white". Finally, the image quality should be enhanced by filling in the small white gaps (less than 5 pixels) that enables a better depiction of the drops. Since the drops appear as circles in the twodimensional view, multiple techniques need to be used to obtain the droplet diameters in pixels, and then compute the actual lengths based on the reference scale provided by the microscope. Figure 3 elaborates the image processing procedure in this study. By knowing the scales of the images, the bubble diameters can be obtained. Ultimately, the following equation is applied to evaluate the $d_{32}$ for all cases with different impellers;

$$
d_{32}=\frac{\sum n_{i} d_{i}^{3}}{\sum n_{i} d_{i}^{2}}
$$

Where $n_{i}$ and $d_{i}$ correspond the number of drops and the nominal diameter of the drops, respectively.

Fig. 3. Overview of image processing procedure

\subsection{Modeling procedure}

\subsubsection{Empirical correlation}

Drop sizes and power consumption were measured for each impeller at different dispersed phase ratio at the same agitation speed. The relation between the drop size, the Weber number and dispersed phase ratio were correlated using equation 4. Therefore, the experimental drop size data were fitted to equation 4 and the corresponding parameters for each impeller were calculated. Two different error functions, the normalized standard deviation $(\Delta q)$ and the nonlinear coefficient of determination $\left(R^{2}\right)$ were applied to evaluate the suitability of equation 4 to the experimental data and adjust each set of drop size model 
parameters. The normalized standard deviation, which measures the deviation between the experimental data and the fitted model values, was evaluated through to the following expression;

$\Delta q(\%)=100 \times \sqrt{\frac{\left.\sum\left[\left(d_{32}\right)_{\text {meas }}-\left(d_{32}\right)_{\text {cal }}\right) /\left(d_{32}\right)_{\text {meas }}\right]^{2}}{n-1}}$

In which, $n$ is the number of data points at a given clearance, and subscripts "meas" and "cal" represent the measured and calculated values of $d_{32}$, respectively. The coefficient of determination, which determines how well the data points fit the model, was calculated as follows;

$$
R^{2}=1-\left(\frac{\sum_{i=1}^{n}\left(d_{32(\text { meas })}-d_{32(\text { cal })}\right)^{2}}{\sum_{i=1}^{n}\left(d_{32(\text { meas })}-{\overline{d_{32(\text { meas })}}}^{2}\right.}\right) \cdot\left(\frac{n-1}{n-p}\right)
$$

where $\overline{d_{32(\text { meas })}}$ is the average value of the experimental data; and $p$ is the number of parameters of the model.

\subsubsection{ANFIS-Fuzzy C-Means}

A fuzzy inference system can be utilized to imitate the characteristics of human decisionmaking capability to accomplish tasks without using detailed numerical computations. Neural networks (NNs) are programs to process information that are motivated by the processes that take place in a brain. NNs are comprised of numerous interrelated computing cells that correspond to the brain neurons. The training algorithm of NNs, make sure that the input data are corresponding to the desired output. Merging fuzzy logic (FL) with NNs has shown promise of such systems in practically emulating the real course of decision-making that an expert does in similar scenarios. During the learning stage of the classical NNs, the weight 
values of the interconnections change only, however, in the hybrid architectures of the two, the learning ability of NNs is united with the inference mechanism of the FL for a neurofuzzy decision-making system [35].

A neural network architecture which includes several connected nodes through directional links is an adaptive network. A node function with constant or variable parameters characterizes each node. To minimize the error, $\mathrm{NN}$ algorithms can be employed to find the unspecified initial and subsequent rule parameters of the fuzzy inference system. This is an "adaptive" system due to this optimization technique. The details of ANFIS technique is given by [36].

Furthermore, in this study, Fuzzy C-means (FCM) is utilized to identify the antecedent membership functions (MF). FCM, introduced by Bezdek (1973), is a method of data clustering which allows one piece of data to belong to two or more clusters. Identifying the data groupings from a set of data to yield a succinct image of a system's behavior is the goal of data clustering [37]. FCM divides a group of $n$ vector $X_{i}, i=1,2, \ldots, n$, into C fuzzy groups, and locates a cluster center in each one while minimizing a cost function of difference measure.

The steps of the FCM algorithm can be briefly explained as follows. At first, the cluster centers $c_{i}, i=1,2, \ldots, C$ randomly from the $\mathrm{n}$ points $\left\{X_{1}, X_{2}, X_{3}, \ldots, X_{n}\right\}$ are chosen. After that the membership matrix $U$ using the following equation is computed:

$$
\mu_{i j}=\frac{1}{\sum_{k=1}^{c}\left(\frac{d_{i j}}{d_{k j}}\right)^{\frac{2}{m-1}}}
$$


where, $d_{i j}=\left\|c_{i}-x_{j}\right\|$ is the Euclidean distance between the $\mathrm{i}^{\text {th }}$ cluster center and $\mathrm{j}^{\text {th }}$ data point (same goes to $d_{k j}$ ), and $m$ is the fuzziness index. Next, the cost function according to the following equation is computed. The process is stopped if it is below a certain threshold.

$$
J\left(U, c_{1}, \ldots, c_{2}\right)=\sum_{i=1}^{c} J_{i}=\sum_{i=1}^{c} \cdot \sum_{j=1}^{n} \mu_{i j}^{m} d_{i j}^{2}
$$

In the final step, a new c fuzzy cluster centers $c_{i}, \quad i=1,2, \ldots, C$ using the following equation is computed:

$$
c_{i}=\frac{\sum_{j=1}^{n} \mu_{i j}^{m} x_{j}}{\sum_{j=1}^{n} \mu_{i j}^{m}}
$$

By using a FCM-based ANFIS approach as well as experimental data, the model was established to predict the drop size. In the model, the target parameter was the drop size, and the Weber number and volume fraction were considered as the input (design) parameters. The experimental data were divided into train $(70 \%)$, validation $(15 \%)$ and test $(15 \%)$ sections for developing the model. The results, which were obtained by the proposed FCM-based ANFIS are discussed in detail in section 3.5.2. Table 3 summarizes the specifications of the designed ANFIS-FCM model.

Table 3. Specifications of the developed ANFIS-FCM model for predicting drop size 


\section{$3 \quad$ Results and discussion}

\subsection{Spatial uniformity of dispersions}

Uniformity was defined through the measurement of drop size at two different positions. The first position was selected at the impeller region and the second at $0.05 \mathrm{~m}$ below the surface. The system of $1 \%$ palm oil in water was chosen as the working media. The agitation speed was set for each impeller to prevent any air entrainment in the tank and apply the same energy dissipation rate. The obtained results verify that $d_{32}$ for all investigated impellers are independent of the sampling position, and they are in a good agreement with Pacek et al. [14]. Therefore, based on the acquired data, the position around the impeller region was applied as the sampling point in the other experiments.

\subsection{Equilibrium time}

A dynamic equilibrium between drops is reached when there is no further change in $d_{32}$ during a breakage and coalescence in a mixing tank, indicating the final drop size distribution $[34,38]$. Commonly, 1 to 3 hours of agitation is required to reach a relative dynamic equilibrium based on the experimental conditions $[6,14]$. Figure 4 illustrates the condition of drops for each impeller at $1,3,5$ and $10 \%$ dispersed phase hold-up and the same power consumption at different agitation periods. An increase in the dispersed phase volume fraction causes slight increase in the dynamic equilibrium time. For most of the employed impellers at $\varphi=0.01$, the drops reached to the equilibrium condition at around 70 minutes of mixing. In the case of $\varphi=0.03$ and 0.05 , the steady state was reached after around 80 to 90 minutes agitation for all studied impellers. The results proved that after 90 minutes of operation, the drop sizes would reach the steady state condition. 


\subsection{Effect of impeller design on drop sizes}

Most of the published work on liquid-liquid mixing accomplished with the Rushton turbine. A comparison between different design of impellers leads to an appropriate choice for a liquid-liquid mixing process. Furthermore, it is applicable to validate the drop size models. The results indicated larger $d_{32}$ for the HE3 impeller at the same energy dissipation rate, while the smallest $d_{32}$ obtained for the DCB impeller. The $d_{32}$ for the HE3 impeller was measured as $136 \mu m$, while the $d_{32}$ for the DCB impeller was $37 \%$ smaller at the same energy dissipation rate. This observation can be explained by the larger swept volume of the DCB impeller compared to other impellers. As expected, at the same energy dissipation rate, the flow discharge and turbulence around the impeller zone are greater for the DCB impeller compared to the other impellers resulting in smaller droplet sizes.

In the case of radial flow impellers, the results indicated smaller drop sizes for the impellers with larger curvature angle. A difference between radial flow and axial flow impellers is the existence of disk blade for the radial flow impellers. This design feature can generate a stronger flow stream in PBTD impeller and results in higher droplet breakage rate and smaller droplet size compared with other axial flow impellers [3, 39, 40]. Turbulence around the PBTD impeller is significantly greater than that of the PBTU impeller due to its flow direction leading to smaller droplet sizes. In addition, the HE3 impeller produced larger droplets as a result of fewer number of blades and flow direction; which caused smaller turbulence and flow intensity around the impeller zone, and lower drop breakage rate. These results clearly verified the effect of the blade shape design on the drop size breakage under the equal energy dissipation rate and experimental condition. A typical cumulative volume distribution of $1 \%$ oil in water system at similar energy dissipation rate for each impeller is illustrated in Figure 5. A variance in breakage mechanisms might be the reason for the 
different cumulative volume distributions for each impellers. These distributions also clearly indicate that the HE3 impeller produces much larger drops compared to the other impellers. Moreover, much wider cumulative volume distributions for HE3, PB, EB and CB impellers proves larger drop sizes for these impellers. The difference in the distribution width indicates the mixing uniformity and flow discharge intensity within the tank. Therefore, it can be concluded that the impeller with narrower cumulative volume distributions are much more suitable for providing smaller and uniform drops within the tank.

Fig. 4. Drops equilibrium time for each impeller in different agitation times and dispersed phase ratios

Fig. 5. Typical Drops sizes distribution for $1 \%$ dispersed phase ratio in a stirred vessel

\subsection{Effect of dispersed phase volume fraction}

Figure 6 demonstrates the effect of the dispersed phase volume fraction for each impeller on the $\mathrm{d}_{32}$. Mixing characteristics are all influenced by the dispersed phase volume fraction. The significant effect of increasing the dispersed phase volume fraction is on the coalescence rate in mixing process [10]. In the present study, the viscosity measurement of the mixtures did not show any significant difference. Therefore, increase in the droplet sizes is not related to increase in coalescence rate due to the viscosity. Figure 6 shows a linear relation between the $d_{32}$ and dispersed phase holdup. It verifies that increase in the dispersed phase volume fraction resulted in larger $d_{32}$ for all the studied impellers. This trend is in a good agreement with El-Hamouz [10], Gabler et al. [41] and Khakpay and Abolghasemi [42]. Such increase in $\mathrm{d}_{32}$ is expected due to higher collision rate between drops, because as the dispensed phase volume fraction was increased, the drop coalescence process was subsequently expedited, and larger drops were produced [7, 8]. Overall, the $d_{32}$ values for 0.01 to 0.05 oil fractions change between 20 and $40 \mu \mathrm{m}$, while the DCB impeller has the lowest variation among the 
impellers with $5 \mu \mathrm{m}$. Further increase in the dispersed phase volume fraction from 0.05 to 0.1 causes about 17 to $32 \mu \mathrm{m}$ change in $\mathrm{d}_{32}$ which shows additional effects of the dispersed phase volume fraction beyond 0.05 . The DCB impeller has the lowest change with $15 \mu m$ while the HE3 impeller has the largest change with $32 \mu \mathrm{m}$ from 0.05 to 0.1 hold-up, which proves better efficiency of DCB impeller in providing similar size droplets in all studied systems. Better performance of DCB impeller in the breakage rate of drops is due to the higher flow intensity around the blades compared to other impellers.

Fig. 6. Effect of dispersed phase volume fraction on dimensionless drop size for all impellers

\subsection{Drop size prediction}

\subsubsection{Empirical correlation}

The drop size and the power consumption were measured for each impeller at different dispersed phase ratios. The relation between the drop size, Weber number and dispersed phase ratio can be correlated by different semi-empirical equations. Equation (4) is selected to correlate the dimensionless Weber number and dispersed phase ratio with drop sizes due to negligible effect of viscosity in this work. Therefore, the experimentally obtained drop sizes were fitted to Equation (4) and the corresponding parameters for each impeller were estimated. A non-linear regression method was also applied at this stage for each studied impeller in order to determine the parameters corresponding to the model, independently. The optimal values of the parameters in the model are summarized in Table 3. In order to compare the quality of the nonlinear regressions for the proposed model quantitatively, the normalized standard deviation $(\Delta q)$ and nonlinear regression coefficient $\left(R^{2}\right)$ were calculated as presented in Table 4. As can be observed, the model parameters for each impeller vary when the dispersed phase ratio and the Weber number change. As stated in the literature, $C_{3}$ 
and $C_{4}$ coefficients depend on the coalescence tendency and the impeller type, respectively. $C_{3}$ is a coefficient particularly related to the liquid-liquid system [43]. The values for $C_{3}$ have been reported in a range of 3 to $20[8,32,33]$. The values for the $C_{4}$ have been reported in the range of 0.047 to 0.184 [43]. The results for the $C_{3}$ and $C_{4}$ are in line with the reported literature. The obtained values for the $C_{3}$ shows that the rate of coalescence in the system is relatively low for all studied impellers. The lower $C_{3}$ value for the DCB ( $\left.\sim 4\right)$ indicates lower coalescence rate, and higher $C_{3}$ value for the HE3 (8.19) suggests higher coalescence rate in the system.

Table 4. Calculated parameters of the proposed drop size correlation and associated $\mathrm{R}^{2}$ and $\Delta \mathrm{q}(\%)$ for different impellers

Based on the calculated values of $\Delta q$ and $R^{2}$ in Table 4 , the proposed model can fit the experimental droplet size data over a broad range of experimental conditions for different impellers.

\subsubsection{ANFIS-FCM model}

In this study, ANFIS-FCM model was utilized to build an alternative, novel prediction model to estimate drop sizes from experimental data using MATLAB environment. A dataset that includes 32 data points was employed. A comparison between estimated values of droplet size by the ANFIS-FCM model and empirical correlation, versus measured values of droplet size is presented in Figure 7. As shown, the results of the ANFIS-FCM model indicates its superiority on predicting performance for the most cases compared to the empirical correlation.

Fig. 7. Prediction capability of ANFIS-FCM model vs. Empirical correlation approach for the whole dataset 
Furthermore, the correlation between estimated the values of drop sizes by the ANFISFCM model and empirical correlation versus the measured values for 32 data sets is presented in Figure 8. This regression plot of the presented ANFIS-FCM model demonstrate a better fit of the results of this model to experimental data points in comparison with the empirical correlations.

Fig. 8. Cross plot of predictions of ANFIS-FCM model vs. corresponding experimental $\mathrm{d}_{32}$ data

Performance analysis of the ANFIS-FCM model for predicting the drop sizes is presented in Table 5. As can be seen, the $R^{2}$ value of the ANFIS-FCM model is the maximum possible, signifying the robustness of the relationship between the predicted and actual values.

According to the calculated values of average relative error (\%ARD), average absolute relative deviation percentage (\%AARD), root mean square error (RSME), and $R^{2}$ as the model evaluation criteria, it can be concluded that the ANFIS-FCM modeling algorithm may be successfully applied for modeling the droplet sizes in immiscible liquid-liquid stirred vessels. Utilizing the presented ANFIS-FCM model provides precise predictions without employing sophisticated methods and expressions.

Table 5. Statistical performance

\section{Conclusion}

Impeller design is one of the determinant factors in mixing performance for various processes. Therefore, drop size measurement, as an indication of mixing performance, was carried out for eight impeller designs in a typical immiscible liquid-liquid system. The results showed that the DCB and PBTD impellers would expedite reaching the equilibrium point 
compared to other tested impellers at the same power consumption. In the case of radial flow impellers, $10 \%$ smaller drop sizes were observed in the impellers with smaller curvature angles. Furthermore, increasing the curvature angle would cause larger swept volume, and more turbulence and flow intensity around the blade zones. Meanwhile, increasing the dispersed phase volume fraction would result in larger $d_{32}$ due to higher collision rate between drops. The impellers with larger swept volumes and higher flow intensity, such as DCB, PBTD and RT, could increase the drop breakage rate. A general semi-empirical correlation was derived through the non-linear regression method. The obtained values for the correlation coefficients in the system featuring the DCB impeller proved lower coalescence rates contrary to the system equipped with the HE3 impeller which showed higher coalescence rates. Further modeling studies using an ANFIS-FCM model were done to predict droplet sizes from experimental data in order to reduce the need for further experiments for similar cases. The results of the ANFIS-FCM model revealed more accurate predictions for most of the cases compared to the empirical correlation and demonstrated the applicability of this method for immiscible liquid-liquid mixing processes. Moreover, the empirical correlation was only able to predict for a range of $1 \%$ to $10 \%$ dispersed phase volume fractions while the ANFIS-FCM model is capable to predict broader ranges due to its built in neural network characteristics.

\section{ACKNOWLEDGEMENTS}

The authors appreciate the financial support provided by the Fundamental Research Grant (FRGS) (FP028-2012A). Special thanks to the Department of Chemical Engineering, Faculty of Engineering, University of Malaya for the resources and facilities provided. 


\section{NOMENCLATURE}

Baffle width, $m$

$C_{1-8} \quad$ Dimensionless constants

C Impeller clearance

$c_{i} \quad$ The d-dimension center of the cluster

$D \quad$ Impeller diameter, $m$

$d_{32} \quad$ Mean diameter of droplets, $m$

$\overline{d_{32 \text { (meas) }}}$ $d_{32(\mathrm{Cal})}$

$d_{i}$

$d_{i j}$

$d_{\max }$

$J_{i}$

m

$N$

$n_{i}$

$n$

$p$

$\Delta q \quad$ Normalized standard deviation

$R^{2} \quad$ Coefficient of determination

$T \quad$ Tank diameter, $m$

We Weber Number, dimensionless

$x_{i} \quad$ The $\mathrm{i}^{\text {th }}$ of d-dimensional measured data

$x_{j} \quad$ The $\mathrm{i}^{\text {th }}$ of d-dimensional measured data

\section{Greek Letters}

$\varphi_{d} \quad$ Dispersed phase volume fraction or holdup, $\%$

$\rho_{c} \quad$ Continuous phase density, $\mathrm{kg} \mathrm{m}^{-3}$

$\rho_{d} \quad$ Dispersed phase density, $\mathrm{kg} \mathrm{m}^{-3}$

$\mu_{d} \quad$ Dispersed phase viscosity, $\mathrm{kg} \mathrm{m}^{-1} \mathrm{~s}^{-1}$

$\mu_{i j} \quad$ Membership matrix

$\sigma \quad$ Interfacial tension, $N / m$

\section{Subscripts}

$\begin{array}{ll}i & \text { Cluster center } \\ j & \text { Data point } \\ k & \text { Iteration step }\end{array}$




\section{References}

[1] Maaß S, Gäbler A, Wegener M, Zaccone A, Paschedag A, Kraume M. Drop breakage and daughter drop distributions in stirred liquid/liquid systems and their modelling within the population balance equation. Chem Eng Res Des 2007; 85: 703.

[2] Maaß S, Wollny S, Voigt A, Kraume M. Experimental comparison of measurement techniques for drop size distributions in liquid/liquid dispersions. Experiments in Fluids 2010; 50: 1-11.

[3] Giapos A, Pachatouridis C, Stamatoudis M. Effect of the Number of Impeller Blades on the Drop Sizes in Agitated Dispersions. Chem Eng Res Des 2005; 83 (12): 14251430

[4] Abdul Raman, A. A., N. Sulaiman, N. M., Ibrahim, S. and Sethu, V. Bubble size distribution: comparison between six-bladed curve blade impeller and Rushton Turbine. Malaysian J Chem Eng 2007; 1: 163-170.

[5] Patil P, Kumar S. Breakup of drops around the edges of Rushton turbine. Can J Chem Eng 2010; 88, (6): 912-918.

[6] El-Hamouz A. Effect of Surfactant Concentration and Operating Temperature on the Drop Size Distribution of Silicon Oil Water Dispersion. J Dispers Sci Technol 2007; 28 (5): 797-804.

[7] Sechremeli D, Stampouli A, Stamatoudis M. Comparison of mean drop sizes and drop size distributions in agitated liquid-liquid dispersions produced by disk and open type impellers. Chem Eng J 2006; 117 (2): 117-122.

[8] Kraume M, Gäbler A, Schulze K. Influence of Physical Properties on Drop Size Distribution of Stirred Liquid-Liquid Dispersions. Chem Eng Technol 2004; 27 (3): 330-334.

[9] Paul EL, Atiemo-Obeng VA, Kresta SM. Handbook of industrial mixing. John Wiley \& Sons Inc; 2004.

[10] El-Hamouz A. Drop Size Distribution in a Standard Twin-Impeller Batch Mixer at High Dispersed-Phase Volume Fraction. Chem EngTechnol 2009; 32 (8): 1203-1210.

[11] El-Hamouz A, Cooke M, Kowalski A, Sharratt P. Dispersion of silicone oil in water surfactant solution: Effect of impeller speed, oil viscosity and addition point on drop size distribution. Chem Eng Process 2009; 48 (2): 633-642.

[12] Podgórska W. Influence of the Impeller Type on Drop Size in Liquid-Liquid Dispersion In 13th European Conference on Mixing. London; 2009.

[13] Sis H, Kelbaliyev G, Chander S. Kinetics of Drop Breakage in Stirred Vessels under Turbulent Conditions. J Dispers Sc Technol 2005; 26 (5): 565-573. 
[14] Pacek AW, Chamsart S, Nienow AW, Bakker A. The influence of impeller type on mean drop size and drop size distribution in an agitated vessel. Chem Eng Sci 1999; 54 (19): 4211-4222.

[15] O'Rourke AM, MacLoughlin PF. A comparison of measurement techniques used in the analysis of evolving liquid-liquid dispersions. Chem Eng Proces 2005; 44 (8): 885-894.

[16] Quadros PA, Baptista CMSG. Effective interfacial area in agitated liquid-liquid continuous reactors. Chem Eng Sci 2003; 58 (17): 3935-3945.

[17] Maaß S, Paul N, Kraume M. Influence of the dispersed phase fraction on experimental and predicted drop size distributions in breakage dominated stirred systems. Chem Eng Sci 2012; 76: 140-153.

[18] Zhou G, Kresta S M. Evolution of drop size distribution in liquid-liquid dispersions for various impellers. Chem Eng Sci 1998; 53 (11): 2099-2113.

[19] Beck KJ. Mechanisms of drop break-up in stirred vessels using a sawtooth impeller. Cranfield University, UK; 1998.

[20] Musgrove M, Ruszkowski S, Akker HEA, Derksen JJ. Influence of impeller type and agitation conditions on the drop size of immiscible liquid dispersions. In 10th European Conference on Mixing, Elsevier Science: Amsterdam; 2000: pp 165-172.

[21] Lovick J, Mouza AA, Paras SV, Lye GJ, Angeli P. Drop size distribution in highly concentrated liquid-liquid dispersions using a light back scattering method. J Chem Technol Biotechnol 2005; 80: 545-552.

[22] Afshar Ghotli R, Abdul Aziz AR, Ibrahim S. Effect of Various Curved-Blade Impeller Geometries on Drop Size in a Liquid-Liquid Stirred Vessel. Chem Eng Commun 2017; 204 (8): 884-896.

[23] Kichatov BV, Korshunov AM, Boiko IV, Assorova PV. Effect of Impeller Blade Geometry on Drop Size in Stirring of Immiscible Liquids. Theor Found Chem Eng 2003; 37 (1): 19-24.

[24] Kolmogorov AN. The break-up of droplets in a turbulent stream. Dokl.Akad Nauk 1949; 66: 825-828.

[25] Zaldívar JM, Molga E, Alós MA, Hernández H, Westerterp KR. Aromatic nitrations by mixed acid. Fast liquid-liquid reaction regime. Chem Eng Proces 1996; 35, (2): 91-105.

[26] Nienow AW. Break-up, coalescence and catastrophic phase inversion in turbulent contactors. Adv Colloid Interface Sci 2004; 108-109: 95-103.

[27] Calabrese RV, Wang CY, Bryner NP. Drop breakup in turbulent stirred-tank contactors. Part III: Correlations for mean size and drop size distribution. AIChE J 1986; 32 (4): 677-681. 
[28] Pacek AW, Man CC, Nienow AW. On the Sauter mean diameter and size distributions in turbulent liquid/liquid dispersions in a stirred vessel. Chem Eng Sci 1998; 53 (11): 2005-2011.

[29] Sprow FB. Distribution of drop sizes produced in turbulent liquid--liquid dispersion. Chem Eng Sci 1967; 22 (3): 435-442.

[30] Calabrese RV, Chang TPK, Dang PT. Drop breakup in turbulent stirred-tank contactors. Part I: Effect of dispersed-phase viscosity. AIChE J 1986; 32 (4): 657-666.

[31] Hinze JO. Fundamentals of the hydrodynamic mechanism of splitting in dispersion processes. AIChE J 1955; 1 (3): 289-295.

[32] Carlucci G. Drop size distributions in stirred liquid/liquid systems - Influence of the dispersed phase. Technische Universität Berlin, Berlin; 2010.

[33] Pacek AW, Moore IPT, Nienow AW, Calabrese RV. Video technique for measuring dynamics of liquid-liquid dispersion during phase inversion. AIChE J 1994; 40 (12): 1940-1949.

[34] Zainal Abidin MII, Abdul Raman AA, Mohamad Nor MI. Experimental Investigations in Liquid-Liquid Dispersion System: Effects of Dispersed Phase Viscosity and Impeller Speed. Ind Eng Chem Res 2014; 53: 6554-6561.

[35] Lin CT, Lee CSG. Neural-network-based fuzzy logic control and decision system. IEEE Trans Comput 1991; 40 (12): 1320-1336.

[36] Jang JSR. ANFIS: adaptive-network-based fuzzy inference system. IEEE Trans Syst Man Cybern 1993; 23 (3): 665-685.

[37] Bezdek JC. Fuzzy mathematics in pattern classification. Cornell university; 1973.

[38] Hiraoka S, Kato Y, Tada Y, Ozaki N, Murakami Y, Lee YS. Power Consumption and Mixing Time in an Agitated Vessel with Double Impeller. Chem Eng Res Des 2001; 79 (8): 805-810.

[39] Zhou G, Kresta SM. Impact of tank geometry on the maximum turbulence energy dissipation rate for impellers. AIChE J 1996; 42 (9): 2476-2490.

[40] Rajapakse, A. Drop Size Distributions and Interfacial Area in Reactive Liquid-Liquid Dispersions. RMIT University, Australia, 2007.

[41] Gäbler A, Wegener M, Paschedag AR, Kraume M. The effect of pH on experimental and simulation results of transient drop size distributions in stirred liquid-liquid dispersions. Chem Eng Sci 2006; 61 (9): 3018-3024.

[42] Khakpay A, Abolghasemi H. The effects of impeller speed and holdup on mean drop size in a mixer settler with spiral-type impeller. Can. J. Chemi. Eng. 2010, 88 (3), 329334. 
[43] Angle, C. W.; Hamza, H. A., Drop sizes during turbulent mixing of toluene-heavy oil fractions in water. AIChE J 2006; 52 (7): 2639-2650. 


\section{List of Figures:}

Fig. 1. Experimental setup; A) Motor, B) Shaft, C) Impeller, D) Tank, E) Speed analyzer, F) Power analyzer

Fig. 2. The impeller designs evaluated

Fig. 3: Overview of image processing procedure

Fig. 4. Drops equilibrium time for each impeller in different agitation times and dispersed phase ratios

Fig. 5. Typical drop size distributions for $1 \%$ dispersed phase ratio in a stirred vessel

Fig. 6. Effect of dispersed phase volume fraction on dimensionless drop size for all impellers

Fig. 7. Prediction capability of ANFIS-FCM model vs. Empirical correlation approach for the whole dataset

Fig. 8: Cross plot of predictions of ANFIS-FCM model vs. corresponding experimental $d_{32}$ data 


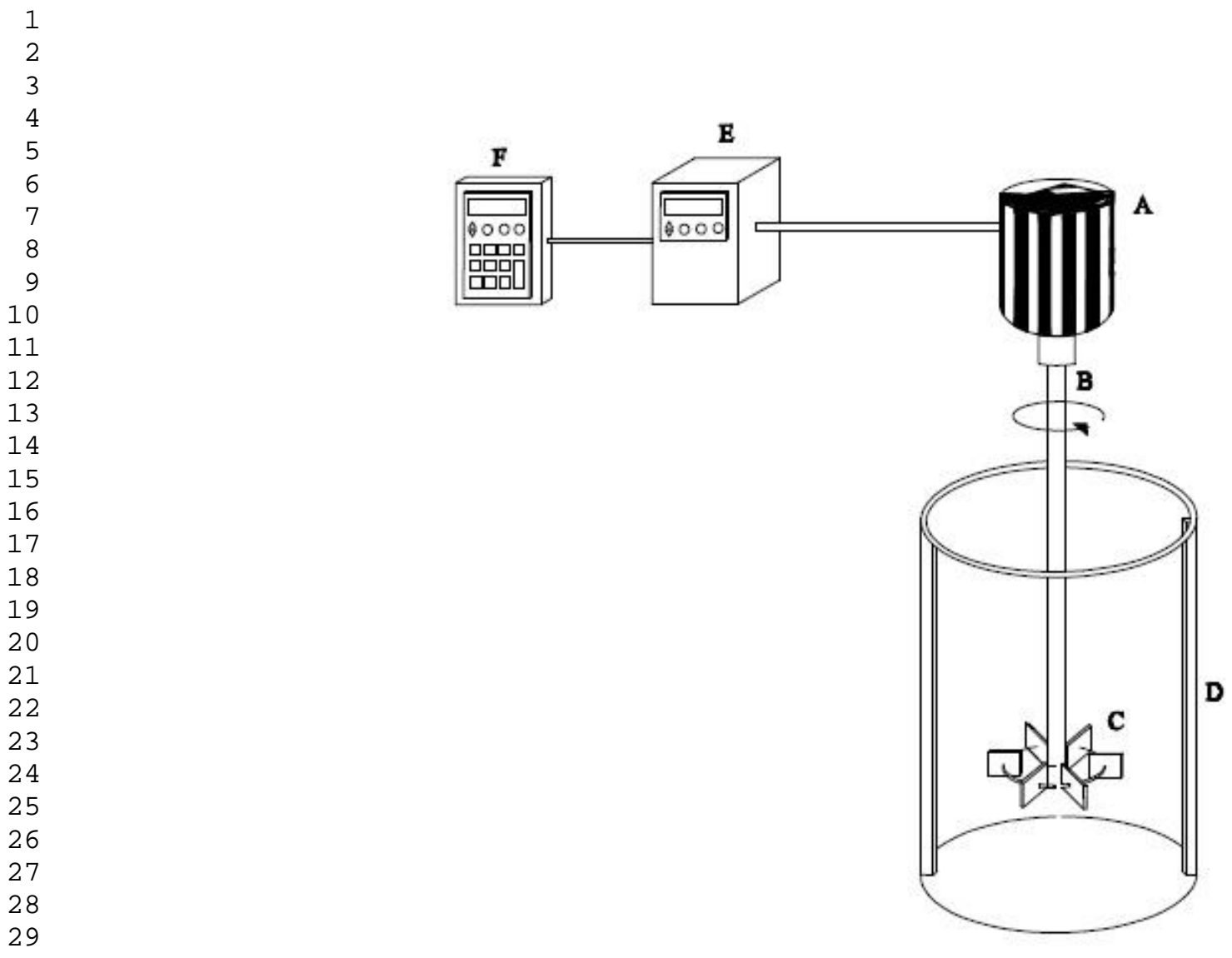

Fig. 1 
1

2

3

4

5

7

8

9

10

11

12

13

14

15

16

17

18

19

20

21

22

23

24

25

26

27

28

29

30

31

32

33

34

35

36

37

38

39

40

41

42

43

44

45

46

47

48

49

50

51

52

53

54

55

56

57

58

59

60

61

62

63

64

65

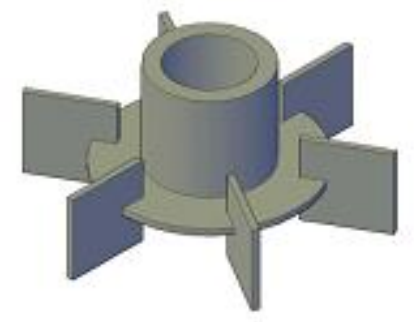

RT

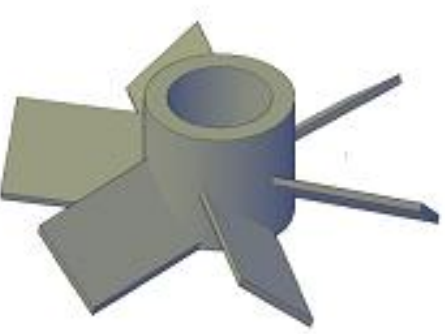

PBTU

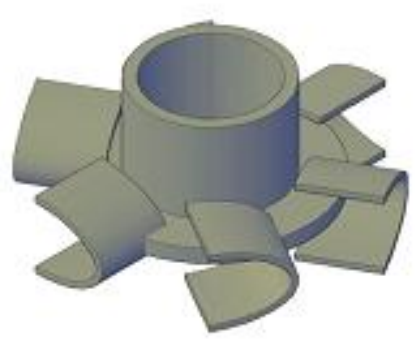

EB

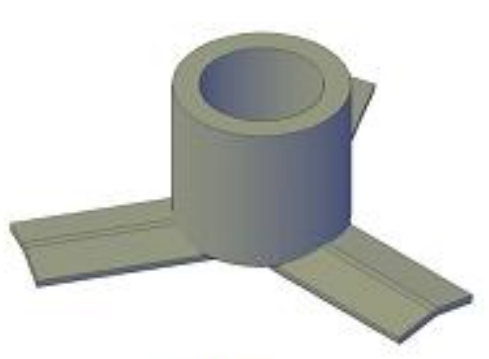

HE3

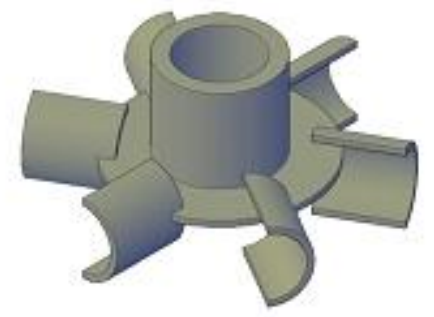

CB

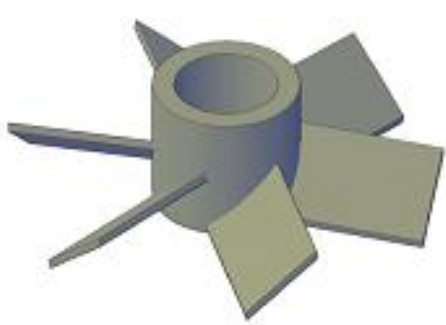

PBTD

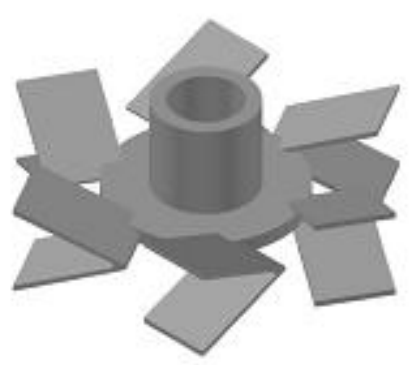

PB

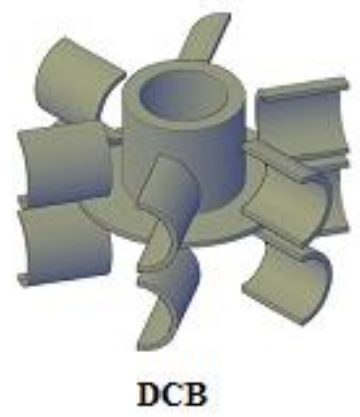

Fig. 2 


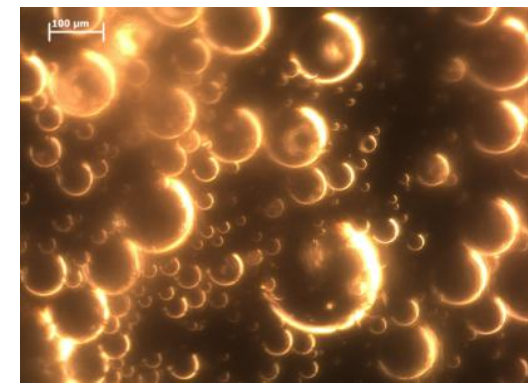

Captured Image

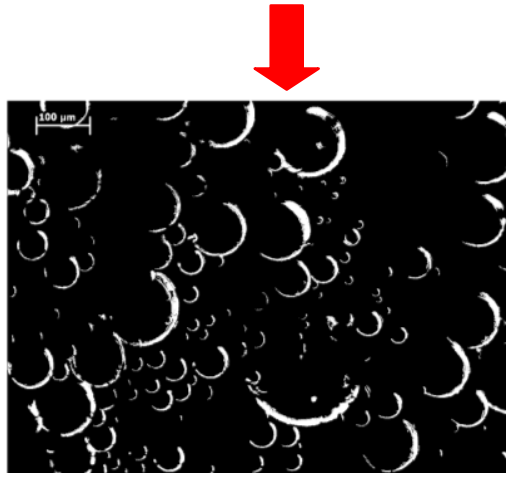

Converted to the binary for

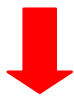

2: Background Subtracted

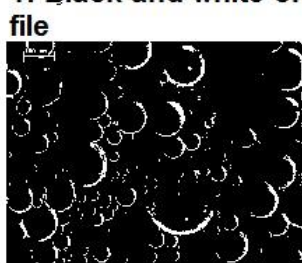

\section{4: Sharpened Image}

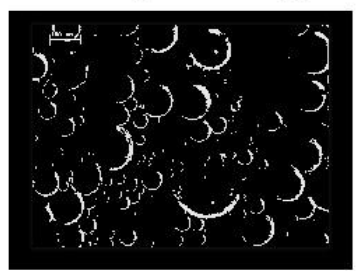

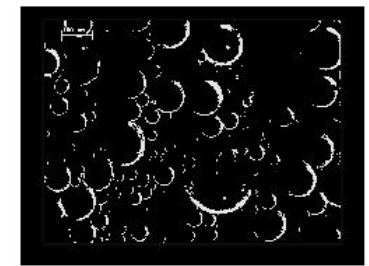

5: Filling Small Holes
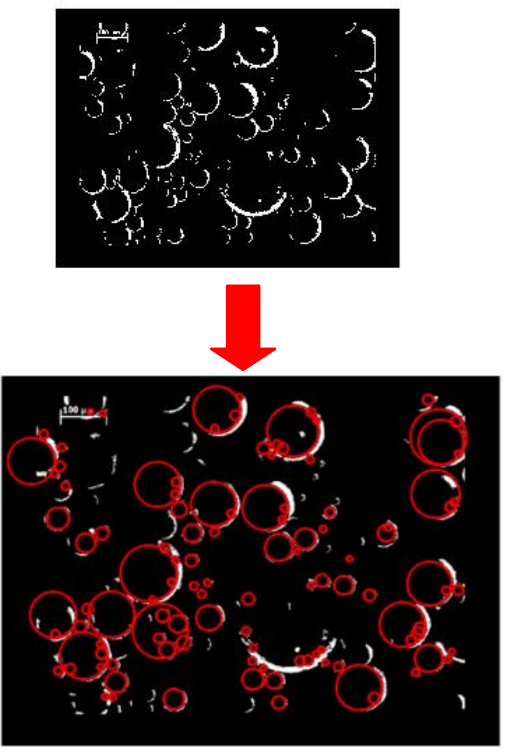

Fig. 3
3: Adjusted Image

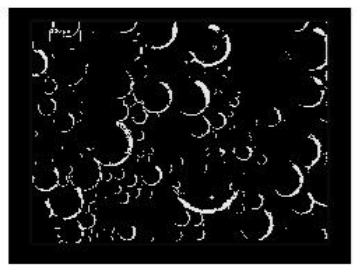

6: 113 Bubbles

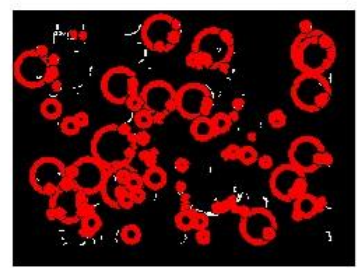



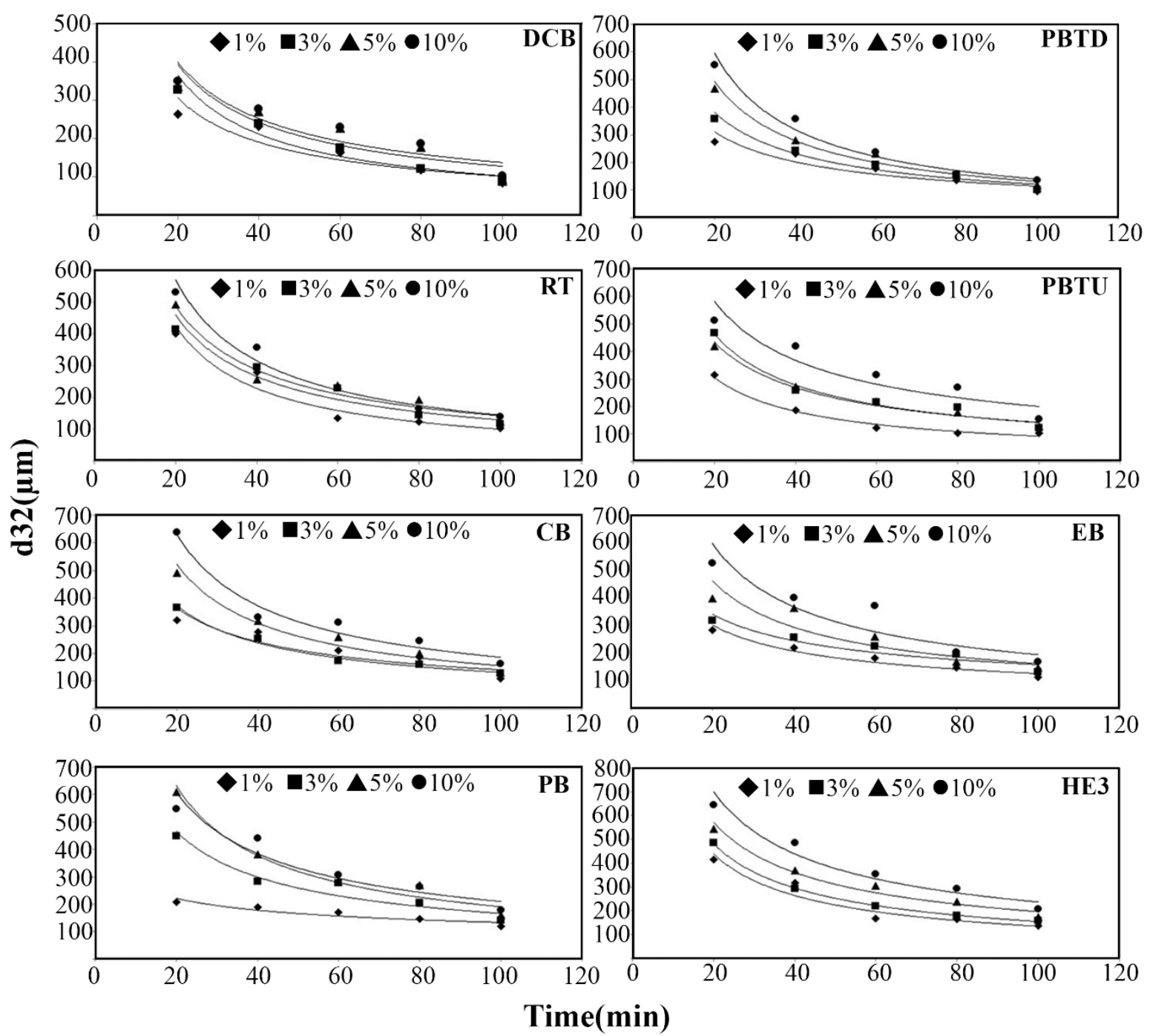

Fig. 4 


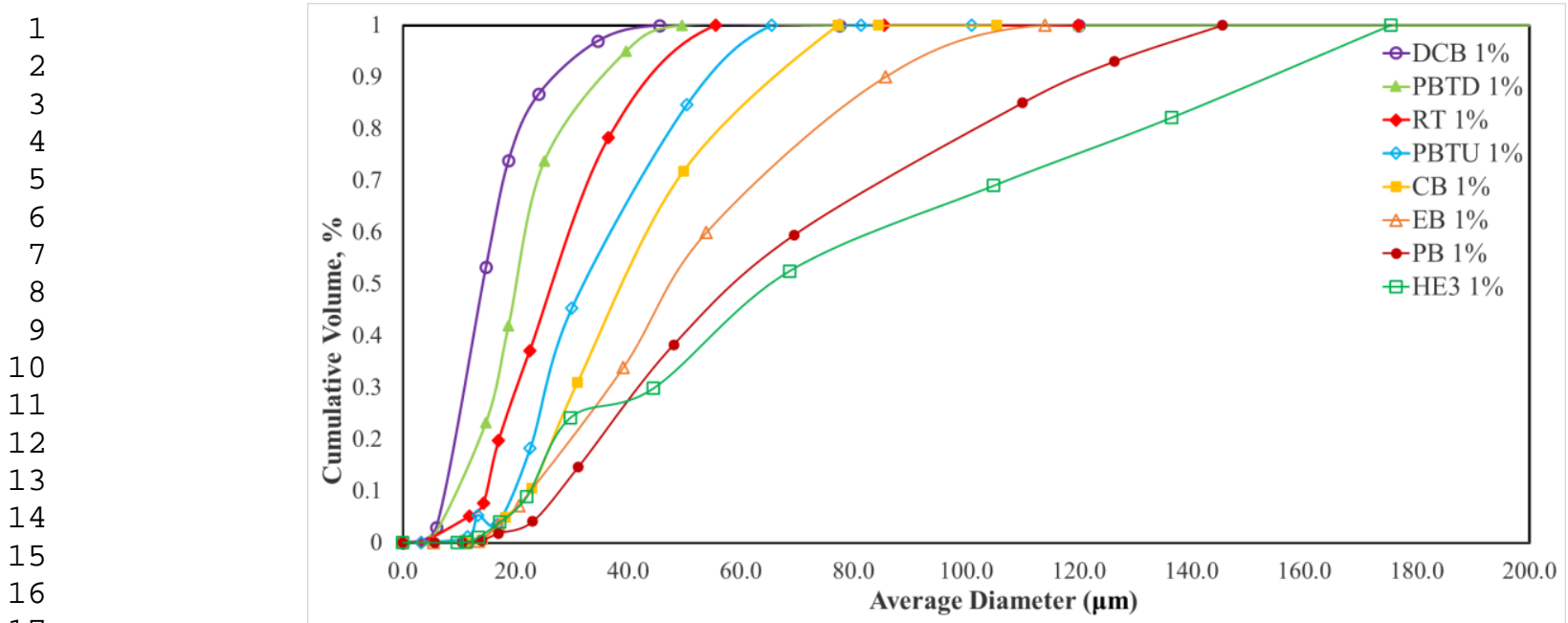

Fig. 5 
1

2

3

4

5

6

7

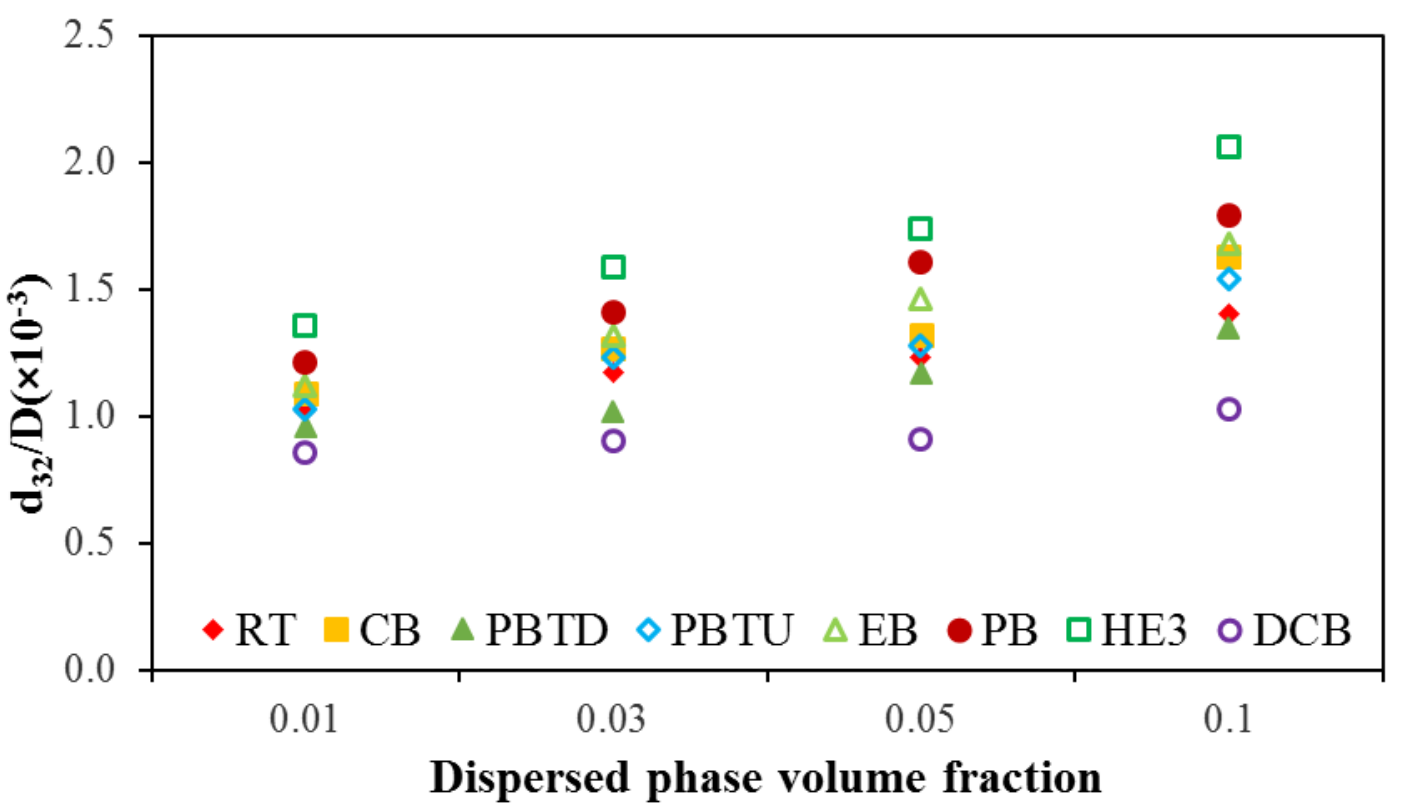

Fig. 6 
1

2

3

4

5

6

7

8

10

11

12

13

14

15

16

17

18

19

20

21

22

23

24

25

26

27

28

29

30

31

32

33

34

35

36

37

38

39

40

41

42

43

44

45

46

47

48

49

50

51

52

53

54

55

56

57

58

59

60

61

62

63

64

65

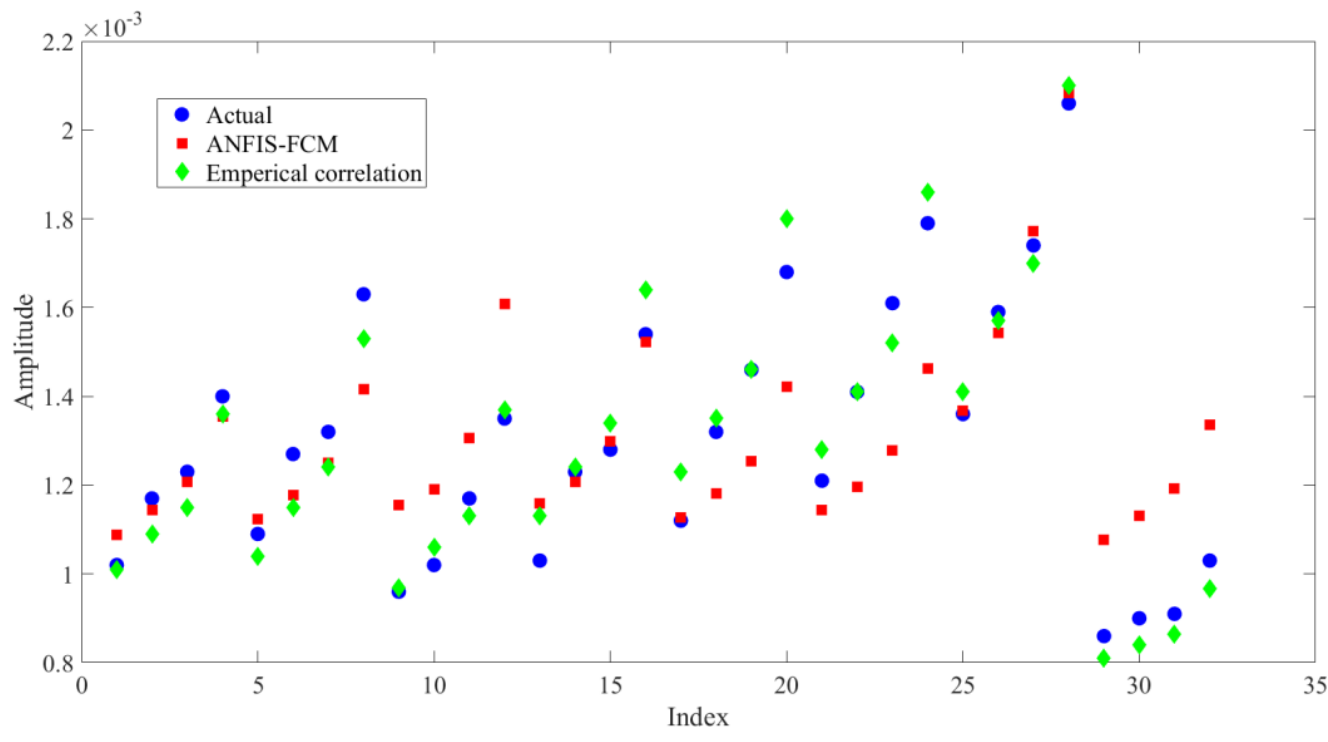

Fig. 7 


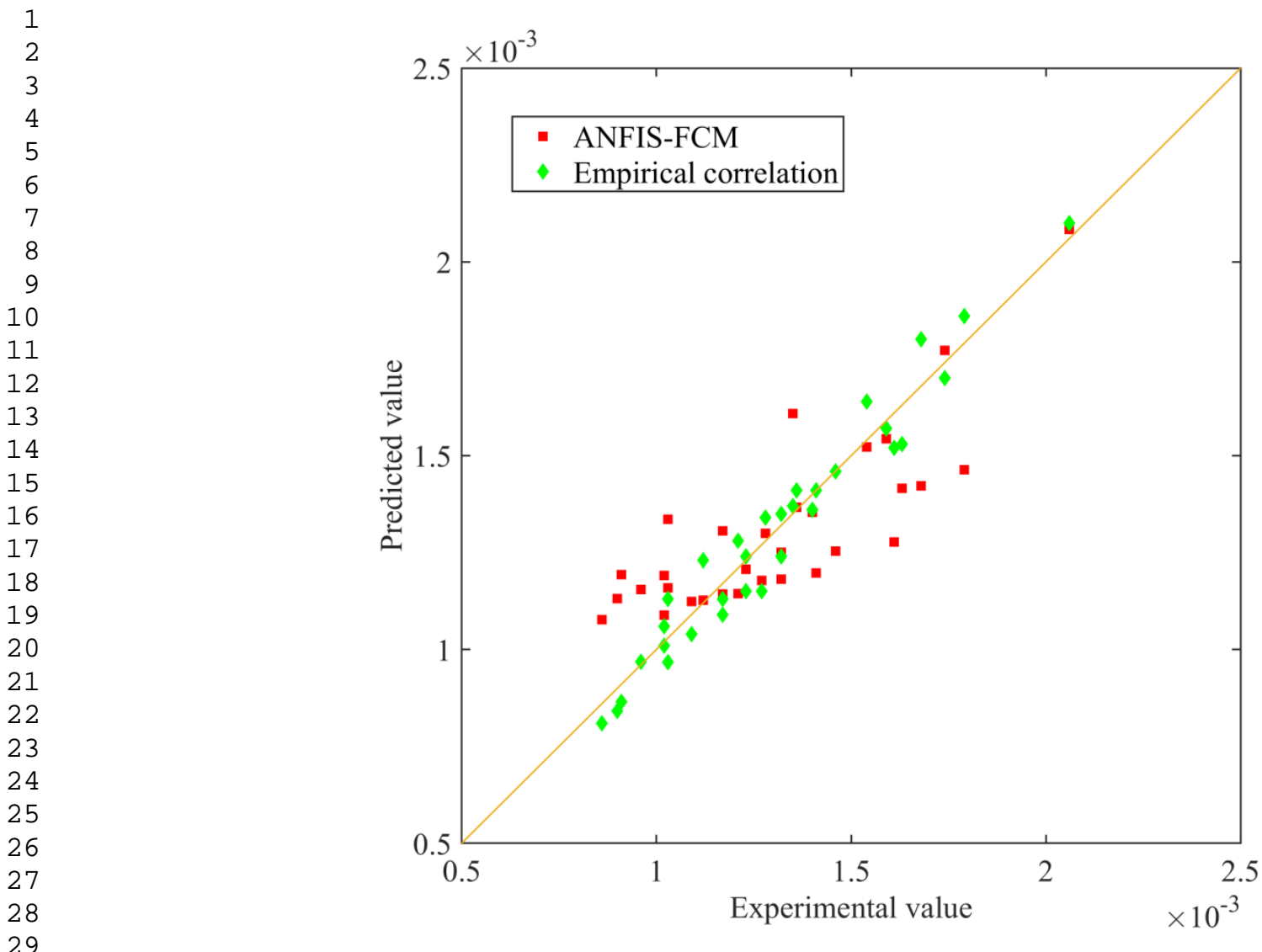

Fig. 8 
Tables

Table 1. Physical properties of the continuous and dispersed phases

\begin{tabular}{|c|c|c|c|c|}
\hline Fluid & $\begin{array}{l}\text { Viscosity } \\
\text { (mPa.S) }\end{array}$ & $\begin{array}{l}\text { Density } \\
(\text { kg.m-3 }\end{array}$ & $\begin{array}{l}\text { Refractive } \\
\text { index }\end{array}$ & $\begin{array}{c}\text { Surface tension } \\
\left(\mathrm{mN} \cdot \mathrm{m}^{-1}\right)\end{array}$ \\
\hline Water & 0.001 & 998.00 & 1.3331 & 68.88 \\
\hline Palm oil & 0.08198 & 890.00 & 1.4645 & 31.44 \\
\hline
\end{tabular}


Table 2. Description of the investigated impellers in the experimental part

\begin{tabular}{cccccccc}
\hline No. $\begin{array}{c}\text { Impeller } \\
\text { Design }\end{array}$ & $\begin{array}{c}\text { Number of } \\
\text { blades }\end{array}$ & $\begin{array}{c}\text { Outer } \\
\text { Diameter } \\
\text { (D) }\end{array}$ & $\begin{array}{c}\text { Central disk Blade length } \\
\text { Size (m) }\end{array}$ & $\begin{array}{c}\text { Blade } \\
\text { (m) }\end{array}$ & C/Tickness (m) & \\
\hline 1 & $\mathrm{RT}$ & 6 & $\mathrm{~T} / 3$ & 0.064 & 0.025 & 0.002 & $1 / 3$ \\
2 & $\mathrm{CB}$ & 6 & $\mathrm{~T} / 3$ & 0.064 & 0.025 & 0.002 & $1 / 3$ \\
3 & $\mathrm{~EB}$ & 6 & $\mathrm{~T} / 3$ & 0.064 & 0.025 & 0.002 & $1 / 3$ \\
4 & $\mathrm{~PB}$ & 6 & $\mathrm{~T} / 3$ & 0.064 & 0.025 & 0.002 & $1 / 3$ \\
5 & $\mathrm{DCB}$ & 6 & $\mathrm{~T} / 3$ & 0.064 & 0.025 & 0.002 & $1 / 3$ \\
6 & $\mathrm{PBTU}$ & 6 & $\mathrm{~T} / 3$ & $\mathrm{~N} / \mathrm{A}$ & 0.035 & 0.002 & $1 / 3$ \\
7 & $\mathrm{PBTD}$ & 6 & $\mathrm{~T} / 3$ & $\mathrm{~N} / \mathrm{A}$ & 0.035 & 0.002 & $1 / 3$ \\
8 & $\mathrm{HE3}$ & 3 & $\mathrm{~T} / 3$ & $\mathrm{~N} / \mathrm{A}$ & 0.035 & 0.002 & $1 / 3$ \\
\hline
\end{tabular}


Table 3. Specifications of the developed ANFIS-FCM model for predicting drop size

\begin{tabular}{cc}
\hline Parameter & Description \\
\hline Number of nodes & 17 \\
Number of linear parameters & 6 \\
Number of nonlinear parameters & 8 \\
Total number of parameters & 14 \\
Number of training data pairs & 22 \\
Number of checking data pairs & 5 \\
Number of epochs & 30 \\
Fuzzy structure & Sugeno \\
Membership function type & Triangular \\
Number of inputs & 2 \\
Number of outputs & 1 \\
Optimization method & Hybrid (least square and back \\
Number of fuzzy rules & propagation technique) \\
& 2 \\
\hline
\end{tabular}


Table 4. Calculated parameters of the proposed droplet size correlation and associated $\mathrm{R}^{2}$ and $\Delta q(\%)$ for different impellers

\begin{tabular}{cccccc}
\hline Impeller Design & $\boldsymbol{\alpha}$ & $\mathbf{C}_{\mathbf{3}}$ & $\mathbf{C}_{\mathbf{4}}$ & $\mathbf{R}^{\mathbf{2}}$ & $\boldsymbol{\Delta q} \mathbf{( \% )}$ \\
\hline RT & -0.6 & 6.1262 & 0.0543 & 0.97 & 3.15 \\
CBT & -0.6 & 7.9306 & 0.0562 & 0.98 & 2.30 \\
PBTD & -0.6 & 7.2358 & 0.0487 & 0.98 & 3.96 \\
PBTU & -0.6 & 7.7046 & 0.0542 & 0.96 & 3.44 \\
EBT & -0.6 & 7.8806 & 0.0591 & 0.95 & 4.02 \\
PBT & -0.6 & 7.644 & 0.0643 & 0.91 & 5.02 \\
DCB & -0.6 & 4.0728 & 0.0450 & 0.99 & 0.74 \\
HE3 & -0.6 & 8.1937 & 0.0708 & 0.98 & 2.91 \\
\hline
\end{tabular}


Table 5. Statistical performance

\begin{tabular}{ccccc}
\hline & RMSE & AARD & ARD & $\mathbf{R}^{\mathbf{2}}$ \\
\hline ANFIS-FCM & 0 & 10.809 & -2.158 & 1 \\
Empirical correlation & 0 & 4.434 & 0.529 & 0.993
\end{tabular}


Supplementary Material
Click here to download Supplementary Material: Supplementary Material.xIsx

(n)

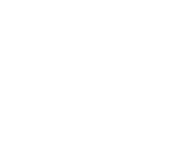

(1)

$\sqrt{3}$

(1)

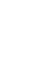

(1)

$\sqrt{2}$




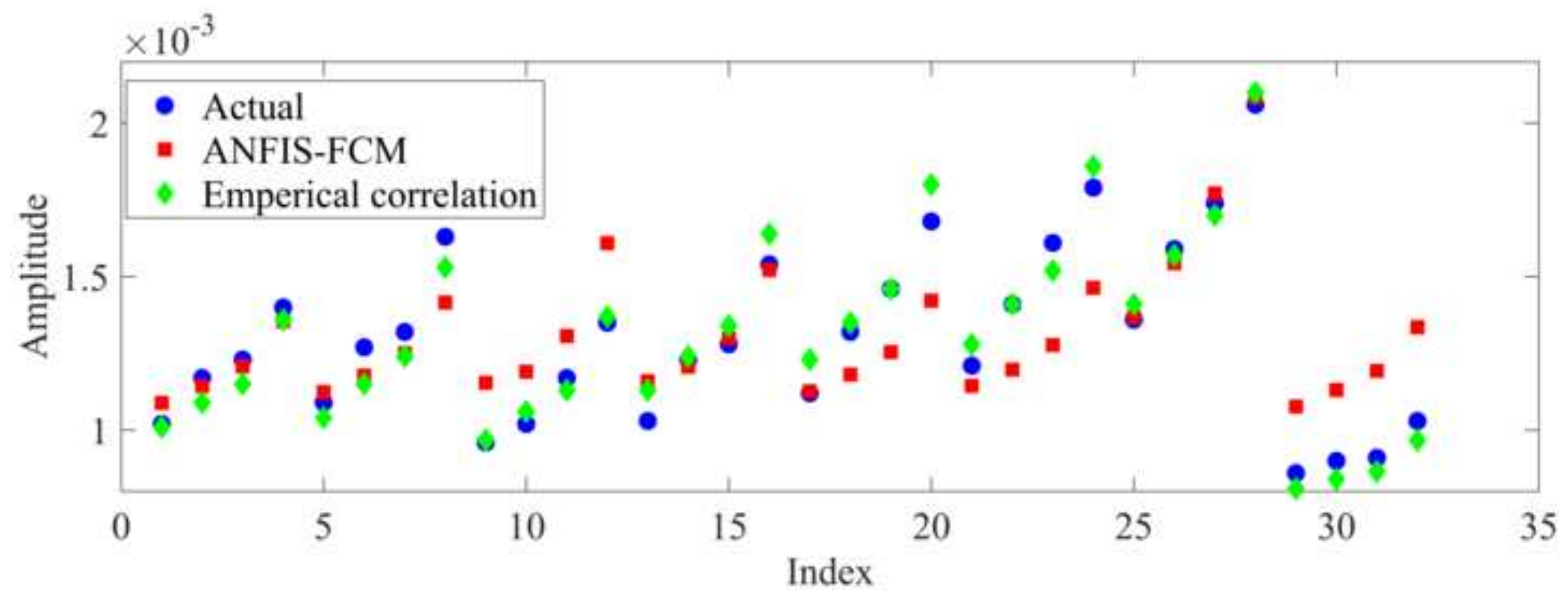

